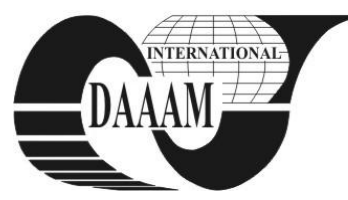

Annals of DAAAM for 2011 \& Proceedings of the 22nd International DAAAM Symposium, Volume 22, No. 1, ISSN 1726-9679 ISBN 978-3-901509-83-4, Editor B. Katalinic, Published by DAAAM International, Vienna, Austria, EU, 2011 Make Harmony between Technology and Nature, and Your Mind will Fly Free as a Bird Annals \& Proceedings of DAAAM International 2011

\title{
INTELLIGENT ROBOTIC SYSTEMS IN SURGERY
}

\author{
COVO, P[etar]; GRZAN, M[arijan] \& COVO, A[na]
}

\begin{abstract}
Modern medicine is one of the prime movers initiating the development of new technologies within which the application of robots is of quite new and special significance. The robotic system - ROKI was designed and developed to assist at operations in surgery. It can be controlled by preprogrammed routines, by joystick located in the control console or by voice control. By designing and manufacture of the robotic system for assistance in surgery the following objectives have been achieved: 1) designing, developing and manufacture of a robot for the assistance in surgery; 2) designing and development of $S W$ support for the control and integration of the robot in the operation room environment; 3) applying $H W$ and $S W$ modular assembly a few robot variants were worked out; 4) all phases were integrated; 5) testing and finishing of the prototype fabricated and the optimization of work and control parameters. The system simulated behavior and probable control algorithms were tested on the prototype (Fig.1.). The tests were based on the measurements and analysis of the signals of control and check elements. The accuracy positioning depends mostly on the flexible deformations of the robot arm and results repeatability within $\pm 0.02 \mathrm{~mm}$ tolerance range, at the maximum acceleration. The tests made on the robot prototype confirmed the adequacy of the methods applied and tools used. The development of control system, together with the development of safety, should undergo further research in order to set the conditions for greater influence of a man in the joint work with these structure robots types.

Key words: robotic system, surgery
\end{abstract}

\section{INTRODUCTION}

The robotic system - ROKI was designed and developed to assist at operations in surgery within the project financed by the Croatian Institute of Technology covered by TEST program. The project was managed by the University of Zadar that formed a project team of 11 researches who defined and make a conceptual design. The conceptual design development, designing and manufacture, as well as the control and final tests of this robotic system were carried out in HSTEC Zadar.

This robot prototype was developed for the first level of application, and in this way the necessary conditions have been fulfilled to use a robot in surgery and other medical fields, especially in laboratories, patient rehabilitation and education, as well as in related pharmaceutical industry where adequately "equipped" robots can successfully replace a man in adverse and dangerous situations for him. Modern HW and SW were applied at the designing of the robot, where the application of simulation and generally digital and virtual production adequately reduced the time necessary to develop and fabricate the robot. Knowledge and experiences gained during the project execution will set the conditions necessary for the second level of the robot application in surgery. Šoša, T. at. all. (2007)

Highly sophisticated robotic equipment assists a surgeon in operations by producing an image of an operative section through a special camera, and by holding, in a specially designed robot arm, surgical instruments or even the heart being operated. ROKI may be controlled by preprogrammed routines, and by joystick located in the control console. Touch-panel on the console enables easy handling where the control is carried out easily with four rotary and one linear robot axes. Voice control is also possible and this facilitates the work of a surgeon during the operation to a great extent. During the operation, the robotic system makes a video recording of a complete operation and files it in its own database. Udiljak, T. at all., (2007),

\section{MANUFACTURE PROCEDURE}

By designing and manufacture of the robotic system for assistance in surgery the following objectives have been achieved: 1) designing, developing and manufacture of a robot for the assistance in surgery; 2) designing and development of SW support for the control and integration of the robot in the operation room environment; 3) applying HW and SW modular assembly a few robot variants were worked out; 4) all phases were integrated; 5) testing and finishing of the prototype fabricated and the optimization of work and control parameters.

Defined operations at the prototype manufacture are: 1) system conceptual design project; 2) control system designing; 3) virtual robotic system model designing and simulation; 4) preparation of technical documentation; 5) purchase of standard components; 6) fabrication of structural elements; 7) necessary control software engineering; 8) prototype assembling; 9) prototype testing; 10) work and control parametres adjusting and optimization; 11) preparation of documentation to initiate the procedure for the obtaining of a preliminary permit for clinical testing in Croatia.

The result measurableness is divided in four phases: $1^{\text {st }}$ phase: a) system conceptual design project, b) control system designing, c) virtual robotic system model and operation simulation; $2^{\text {nd }}$ phase: a) preparation of technical documentation, b) purchase of standard components and eleboration of the system variants; $3^{\text {rd }}$ phase: a) fabrication of structural elements, b) necessary control software (program support) engineering for the system control and integration and prototype assembling; $4^{\text {th }}$ phase: a) prototype testing under laboratory and clinical conditions, b) system finishing-up and optimization.

The project innovativeness and originality are based on the adoption of new knowledge in the fields of: 1) designing and application of robotic systems; 2) application of voice control in the control of robots; 3 ) human-robot interaction in surgery.

Contribution to the Croatian technological developments is based on the successful development of a new, export-oriented product made after innovative actions and strategic planning. The project contributes to the productivity rise in general, export competitiveness based on the investments in knowledge. The prototype of a robotic module for the assistance in surgery may become a competitive export product, while the innovative components for new technologies may become the basis for the rise in the competitiveness of Croatian companies that want to automate and improve their production.

Potential users of the robotic module for the assistance in surgery are hospitals and other health institutions in the country, as well as faculties and educational institutions of medicine. Some project results may generally be used in the robot application and development.

The project validation is based on the establishment of new, interdisciplinary knowledge and teams for the implementation of robotics in medicine and other fields of human activity. 
According to the analyses made, there exists a strong interest in this project in the country, as well as abroad. The project usefulness is in the development and the realization of an innovative market and export-oriented high-tech product.

After the prototype of the robotic system for the assistance and auxiliary operations in surgery has been completed, it is necessary to complete the documentation in compliance with ISO 13485 and prepare documentation to initiate the procedure to obtain the preliminary permit for clinical tests in Croatia in accordance with the Law on Medicines and Medical Devices (Official Journal No. 121/03 and No. 177/04) and the Rules on Clinical Tests and Good Clinical Practice (Official Journal No. 175/03 and No. 55/04).

\section{TEST RESULTS}

When the system was being planned and designed, special attention was paid to the flexibility of a modular concept that offers a wide variety of applications. The $\mathrm{Z}$-axis shift creates the space ready to accommodate medical instruments, units for a device handling and mounting. Altintas, . at all. (2005)

The system simulated behavior and probable control algorithms were tested on the prototype (Fig.1.). The tests were based on the measurements and analysis of the signals of control and check elements.

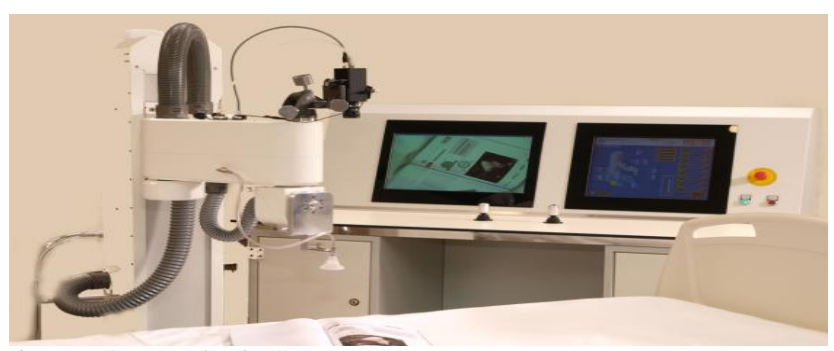

Fig.1. ROKI Robotic System prototype

The accuracy positioning depends mostly on the flexible deformations of the robot arm and results repeatability within \pm $0.02 \mathrm{~mm}$ tolerance range, at the maximum acceleration. In the next step it is planned that the quality of a variety of processing procedures by motorspindle in both variants (motorspindle in motion and fixed) for the operation processing is tested. Watanabe, A. at all. (2005)

An application functional limit in medicine should be minimized when the robotic systems of this kind are developed, although the costs of implementation, a set of applications for non-structured and often varying composed programs (educational staff), modifications and limited productions are high. On the other hand, conventional equipment handling is considerably limited as regards efficiency, accuracy and safety issues.

\section{OPERATING ROOM}

An operating room is a room specially designed for surgery. To meet the requirements this room should: 1) be separated from patient ward and outside world, 2) be technically and infrastructurally equipped for surgery, 3) meet standardized room and sanitary conditions, 4) have available all necessary anterooms enabling free and safe taking patients in and out, anesthesiological preparation and wakening after an operation, washing and sterilization of instruments, and storing of surgical supplies and medicines. Brunicardi, F. C. at all. (2009)

Success in treating of any illness requiring surgery depends on adequate use of elementary knowledge at diagnostic assessment, adequate pre-surgery preparation and continuing care of patients prior and after the surgery. A true care and understanding of the patient's problems make a surgeon a doctor. Taking into consideration invaluable importance of the psychosomatic component, a surgeon: 1) should clearly inform the patient on the nature of his illness, 2) should clarify basic principles of the operation, 3) should document his decision to perform the operation, 4) should provide an explanation that has to be in compliance with Evidence Based Medicine (EBM), 5) when explaining an indication, it is useful to call, with the permission of the patient, a family conference to make jointly the best decision to the benefit of the patient when the immediate family is present, 6) should make psychological preparation in the atmosphere of mutual trust, which considerably effects the patient's will to live, as well as the whole body protectiveimmunological system during operation. By adopting a robotic system for assistance in surgery, a new form of education will be adopted, too.

The above-mentioned duties are primarily parts of medical ethics and vocation, and today they are additionally regulated by law (written consent by patient or guardian).

Modern operating room design has been developing since the time when the operations were performed at the patient's home, then in the surgery clinic or in the tent near battlefield, and to present day when special rooms are designed in such a way that offer optimum conditions enabling the operation performance at the minimum risk. The appropriate room design is necessary not only for immediate medical treatment of the patient and the provision of adequate environment for the staff included in the treatment, but also that all the supplies necessary for the operation are put into it. The staff that should be present in the operating room consists of a surgeon, assistants, anesthesiologist, instrument nurses, anesthesia technicians and perfusionists. In addition to the above there are attendants who do the cleaning of the operating room and surgical ward, then attendants maintaining and cleaning the instruments, biomedical engineers, officers in charge for orders and administrative officers, who are very important in providing normal functioning of the ward and operating room. To perform a standard operation there should be at least eight persons in one operating room. In case of complex specialized operations, the number of persons present increases to seventeen.

\section{CONCLUSION}

ROKI, as the first Croatian robotic system for the assistance in surgery, has created preconditions for further innovations in the robotic surgery (in cardiac surgery, bone surgery, neurosurgery) and has made exceptionally positive technological breakthrough in medicine. The robotic system of a designed structure with a vertical movement located in the structure column can successfully support a variety of tasks in the medicine. The tests made on the robot prototype confirmed the adequacy of the methods applied and tools used. The development of control system, together with the development of safety, should undergo further research in order to set the conditions for greater influence of a man in the joint work with these structure robots types.

At the $38^{\text {th }}$ International Showroom of Innovations, New Technologies and Products "GENEVE 2010" in April 2010, the work "The Prototype of a Robotic System for Assistance in Surgery - "ROKI" Z20091863" received 1) Golden Medallion and a Special Acknowledgement of the Jury, 2) Special Award of the National Agency for Scientific Researches of the Romanian Ministry of Education, Research, Youth and Sport.

The results have been obtained within the TEST Technologically research-development projects - program with the support of Croatian Institute of Technology.

\section{REFERENCES:}

Altintas, Y., Brecher, C., Weck, M., Witt, S., (2005), Virtual Machine Tool, Annals of the CIRP.

Šoša, T. at. all. (2007) Surgery, Naklada Ljevak, Zagreb

Udiljak, T. at all., (2007), Intelligent Robot Systems for Flexible Attendance of Machine Tools, 11th International Scientific Conference on Production Engineering -CIM2007

Watanabe, A., Sakakibara, S., Ban, K., Yamada, M., Shen, G., (2005), Autonomous Visual Measurement for Accurate Setting of Workpieces in Robotic Cells, Annals CIP

Watanabe, A. at all. (2005), Autonomous Visual Measurement... Brunicardi, F.C. at all. (2009), Schwartz's Principles of Surgery, 9 Edition, McGraw - Hill professional 